\title{
Ranking of critical success factors in reverse logistics by TOPSIS
}

\begin{abstract}
Environmental issues and governmental regulations have pushed companies to be more environmentally conscious and socially responsible. Sustainable production plays an important role in the global markets and companies practicing sustainable manufacturing processes for protecting the environment can increase their competitiveness. Reverse logistics is one of the sustainable approaches, which returns back used product from point of consumption to the point of origin due to recovery and product reuse. The identification of critical success factors for reverse logistics is essential to facilitate reverse logistics organization in implementing it. In this work, critical success factors (CSFs) in reverse logistics were identified based on the critical success factors in supply chain management. A survey was conducted among reverse logistics experts to identify the factors. Then, the factors were ranked by TOPSIS, showed that transportation as the most important factor followed by process planning and resource efficiency. However, innovation was the lowest ranked.
\end{abstract}

Keyword: Critical success factors (CSFs); Ranking; Reverse logistics 